\title{
NOTES
}

\section{Phenotypic and Phylogenetic Characterization of Some Globicatella-Like Organisms from Human Sources: Description of Facklamia hominis gen. nov., sp. nov.}

\author{
MATTHEW D. COLLINS, ${ }^{1}$ ENEVOLD FALSEN, ${ }^{2}$ JACQUELINE LEMOZY,${ }^{3}$ \\ EVA ÅKERVALL, ${ }^{2}$ BERIT SJÖDÉN, ${ }^{2}$ AND PAUL A. LAWSON ${ }^{1 *}$ \\ Department of Microbiology, BBSRC Institute of Food Research, Reading Laboratory, Reading, United Kingdom ${ }^{1}$; \\ Culture Collection, Department of Clinical Bacteriology, University of Göteborg, Göteborg, Sweden ${ }^{2}$; \\ and Laboratoire de Microbiology, Hospitaux de Toulouse, Toulouse, France ${ }^{3}$
}

\begin{abstract}
Six strains of a hitherto undescribed gram-positive, catalase-negative, facultatively anaerobic coccus from human sources were characterized by phenotypic and molecular taxonomic methods. Comparative 16S rRNA gene sequencing studies demonstrated that the unknown strains were genealogically homogeneous and constitute a new line closely related to, but distinct from, the genus Globicatella. The unknown bacterium was readily distinguished from Globicatella sanguis, the type species of the genus Globicatella, by the results of biochemical tests and an electrophoretic analysis of whole-cell proteins. Based on phylogenetic and phenotypic evidence, we propose that the unknown bacterium be classified as Facklamia hominis gen. nov., sp. nov. The type strain of Facklamia hominis is CCUG 36813.
\end{abstract}

The gram-positive, facultatively anaerobic, catalase-negative cocci form a phenotypically very heterogeneous assortment of organisms. These bacteria invariably possess DNAs with low $\mathrm{G}+\mathrm{C}$ contents. Many but not all of the gram-positive catalasenegative cocci that cause disease in or associated with humans can be readily assigned to the genus Streptococcus or other well-established taxa (e.g., the genus Enterococcus). The taxonomy of the gram-positive catalase-negative cocci has improved a great deal in recent years because of the use of molecular methods. In particular, 16S rRNA sequence comparisons have proved to be invaluable for clarifying the inter- and intrageneric relationships of these bacteria $(4,6,14)$ and have provided an immensely powerful means for recognizing new species and genera of gram-positive cocci $(1-3,5-7)$. In the present study we characterized six strains of a hitherto unknown gram-positive catalase-negative coccus from human sources by using $16 \mathrm{~S}$ rRNA gene sequencing. Based on the phylogenetic results and the phenotypic distinctiveness of the unknown bacterium, a new species, Facklamia hominis, is described.

Five human isolates (CCUG 28572, CCUG 28830, CCUG 32738, CCUG 28829, and CCUG 28827) were referred to the Culture Collection of the University of Göteborg in Göteborg, Sweden, for identification. Strain CCUG 28572 originated from urine from a 7-year-old female, strains CCUG 28830 , CCUG 28829, and CCUG 28827 originated from vaginas, and strain CCUG 32738 originated from blood. The sixth strain (CCUG $36813^{\mathrm{T}}$ ) was recovered from an abscess on the buttocks of a patient in Toulouse Hospital in Toulouse, France. All strains were cultured on Columbia agar (Difco, Detroit, Mich.) supplemented with $5 \%$ sheep blood at $37^{\circ} \mathrm{C}$. The strains were biochemically characterized by using API Rapid ID32 strep and API ZYM systems according to the instructions of the manufacturer (API bioMérieux, Marcy l'Etoile, France).

* Corresponding author. Mailing address: Department of Microbiology, BBSRC Institute of Food Research, Earley Gate, Whiteknights Road, Reading RG6 6BZ, United Kingdom. Phone: (44) 1189357000. Fax: (44) 118 9267917. E-mail: Paul.Lawson@BBSRC.AC.UK.
Polyacrylamide gel electrophoresis of whole-cell proteins was performed as described previously (12). For densitometric analysis, normalization, and interpretation of protein patterns the Gelcompar GCW 3.0 software package (Applied Maths, Kortrijk, Belgium) was used. The cell wall murein type and DNA base composition of strain CCUG $36813^{\mathrm{T}}$ were determined as described by Schleifer and Kandler (13) and Garvie (10), respectively. A phylogenetic analysis was performed by comparing $16 \mathrm{~S}$ rRNA gene sequences. A large fragment of the 16S rRNA gene was amplified by PCR by using universal primers pA (positions 8 to 28 [Escherichia coli numbering]) and $\mathrm{pH}^{*}$ (positions 1542 to 1522 ). The PCR products were purified by using a PrepA-Gene kit (Bio-Rad, Hercules, Calif.) according to the manufacturer's instructions and were directly sequenced by using a Taq DyeDeoxy terminator cycle sequencing kit (Applied Biosystems, Foster City, Calif.) and an automatic DNA sequencer (model 373A; Applied Biosystems). The closest known relatives of the new isolates were determined by performing a database search with the program FASTA of the Genetics Computer Group package (8). The sequences of the closely related organisms and the sequences of other known related strains were retrieved from the EMBL and Ribosomal Database Project libraries and were aligned with the newly determined sequences by using the program PILEUP (8). The resulting multiple sequence alignment was corrected manually, and approximately 100 bases at the $5^{\prime}$ end of the rRNA were omitted from further analyses because of alignment ambiguities. A continuous stretch of 1,320 bases was used for the distance matrix analysis. A distance matrix was constructed by using the programs PRETTY (8) and DNADIST (using the Kimura-2 correction parameter) (9). A phylogenetic tree was constructed by the neighbor-joining method with the program NEIGHBOR (9). The stability of the groups was estimated by performing a bootstrap analysis (500 replications) with the programs DNABOOT, DNADIST, NEIGHBOR, and CONSENSE (9). In addition, a parsimony analysis (9) was performed with the same data set.

Cells of the six isolates from humans were ovoid and formed pairs or groups. All of the strains were gram-positive, catalase- 


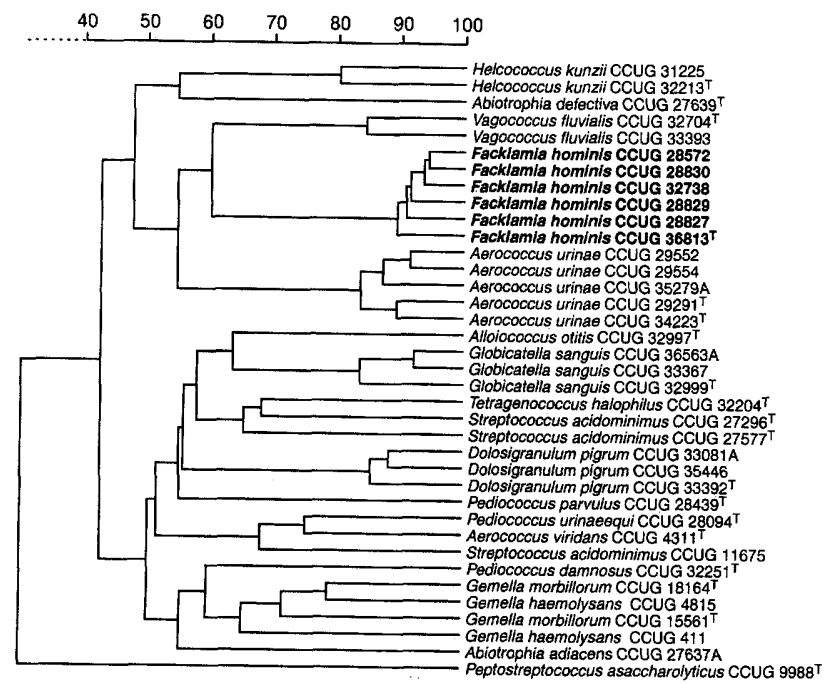

FIG. 1. Similarity dendrogram based on whole-cell protein patterns of $F$. hominis sp. nov. and related species. Levels of correlation are expressed as percentages of similarity.

negative facultative anaerobes which produced weakly alpha-hemolytic colonies on horse blood. All of the strains resembled each other in hydrolyzing hippurate and producing arginine dihydrolase and leucine arylamidase. None of the strains produced alkaline phosphatase, alanylphenylalanyl-proline arylamidase, $\beta$-glucuronidase, $\beta$-glucosidase, or $\beta$-mannosidase. All of the strains were remarkably unreactive toward sugars and failed to produce acid from L-arabinose, D-arabitol, cellobiose, glucose, glycogen, lactose, maltose, D-mannose, melibiose, melezitose, mannitol, lactose, pullulan, D-raffinose, D-ribose, sorbitol, sucrose, D-xylose, L-xylose, D-tagatose, and trehalose. The close phenotypic affinity of the clinical isolates was confirmed by the results of the polyacrylamide gel electrophoresis analysis of whole-cell proteins; the six strains formed a distinct cluster quite separate from the other catalase-negative spheroid organisms examined (Fig. 1).

An examination of the cell wall murein of a representative strain (CCUG $36813^{\mathrm{T}}$ ) of the unknown coccus revealed that lysine was the dibasic amino acid and that the wall type was Lys-D-Asp (type A4 $\alpha$ according to nomenclature of Schleifer and Kandler [13]). This murein structure is quite common among gram-positive catalase-negative cocci and occurs, for example, in Dolosigranulum pigrum (3), Lactosphaera pasteurii (11), and some enterococci, lactococci, pediococci, and streptococci (13). However, the wall type of the unknown coccus is distinct from that of Alloiococcus otitis (1), Globicatella sanguis (5), Abiotrophia defectiva (11), and aerococci (2), all of which possess a murein that is lysine directly cross-linked (type A1 $\alpha$ ).

To establish the phylogenetic position of the unknown bacterium from humans, the 16S rRNA genes of the six strains were amplified by PCR and were characterized by performing a sequence analysis. The almost complete gene sequence ( $>1,400$ nucleotides) of strain CCUG $36813^{\mathrm{T}}$ was determined, and sequence searches of the EMBL and GenBank libraries with the FASTA program revealed that the new organism was phylogenetically most closely associated with the lactic acid group of bacteria. The sequences of the nearest relatives of the unknown organism were retrieved from the EMBL and GenBank libraries and subjected to a comparative analysis to determine the phylogenetic position of strain CCUG $36813^{\mathrm{T}}$. A tree constructed by the neighbor-joining method which indicates the phylogenetic affinity of the unknown coccus within the lactic acid bacteria is shown in Fig. 2, and the levels of
TABLE 1 . Levels of 16S rRNA similarity between $F$. hominis sp. nov. and some related lactic acid bacteria

\begin{tabular}{l} 
Species \\
$\begin{array}{l}\text { \% Sequence similarity } \\
\text { with } F . \text { hominis }\end{array}$ \\
\hline Abiotrophia adiacens (D50540)
\end{tabular}

${ }^{a}$ Based on a comparison of approximately 1,320 bases.

${ }^{b}$ The numbers in parentheses are EMBL and GenBank database accession numbers.

sequence similarity between close relatives are given in Table 1. The unknown coccus formed a distinct line that exhibited a specific phylogenetic association (level of 16S rRNA sequence divergence, approximately $6.3 \%$ ) with $G$. sanguis. Bootstrap resampling (bootstrap value, $100 \%$ ) revealed that this association was statistically highly significant. Abiotrophia defectiva exhibited a somewhat more distant association (level of $16 \mathrm{~S}$ rRNA sequence divergence, approximately $8 \%$ ) with the unknown coccus. Bootstrap resampling showed that the grouping of Abiotrophia defectiva with the unknown organism and the $G$. sanguis cluster was robust (bootstrap value, 100\%). A parsimony analysis was also performed, and all significant associations (Fig. 2) were confirmed (data not shown). To assess the genotypic relatedness of the human isolates, partial 16S rRNA gene sequencing was performed. A short stretch of approximately 500 bases that included variable regions V1 to V3 and contained highly characteristic sequences was examined for

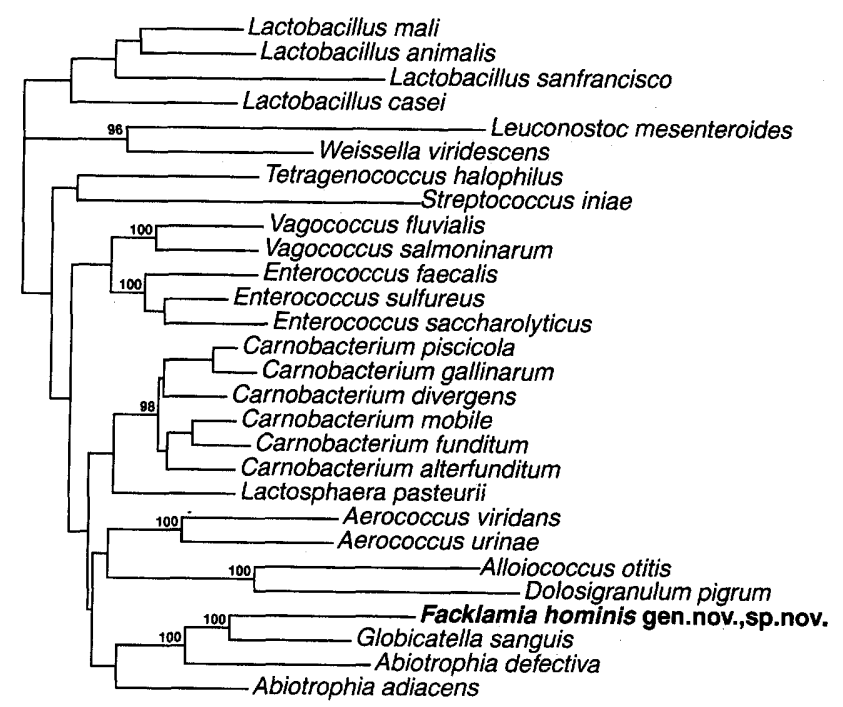

FIG. 2. Unrooted tree showing the phylogenetic relationships of $F$. hominis sp. nov. and some other low-G+C-content gram-positive bacteria. The tree was constructed by using the neighbor-joining method and was based on the results of a comparison of approximately 1,320 nucleotides. Bootstrap values, expressed as percentages of 500 replications, are indicated at branch points. 
TABLE 2. Characteristics that differentiate $F$. hominis from $G$. sanguis

\begin{tabular}{lcc}
\hline \multicolumn{1}{c}{ Characteristic } & F. hominis & G. sanguis \\
\hline Production of acid from: & $-a$ & \\
Glycogen & - & + \\
Lactose & - & $\mathrm{V}$ \\
Maltose & - & + \\
Mannitol & - & + \\
Melibiose & - & + \\
Methyl- $\beta$-D-glucopyranoside & - & $\mathrm{V}$ \\
Pullulan & - & $\mathrm{V}$ \\
Raffinose & - & + \\
Ribose & - & + \\
Sorbitol & - & $\mathrm{V}$ \\
Sucrose & - & + \\
Trehalose & & + \\
Production of: & + & - \\
Arginine dihydrolase & - & $\mathrm{V}$ \\
$\beta-$-Glucosidase & $\mathrm{V}$ & - \\
Urease & $\mathrm{A} 4 \alpha$ & $\mathrm{A} 1 \alpha$ \\
Murein type & & \\
\hline
\end{tabular}

${ }^{a}-$, negative; + , positive; $\mathrm{V}$, variable.

five strains. The $16 \mathrm{~S}$ rRNAs of these strains were found to be identical to CCUG $36813^{\mathrm{T}} 16 \mathrm{~S}$ rRNA, thereby demonstrating that there is a close genealogical affinity among the isolates.

The unknown isolates from human clinical sources clearly belong to a hitherto unrecognized gram-positive catalase-negative species within the lactic acid group of bacteria. From the 16S rRNA sequence analysis results it is evident that this bacterium has a close phylogenetic relationship with $G$. sanguis. Although the association between these taxa is significant, the sequence divergence value of $>6 \%$ suggests that this relationship is a relationship between two phylogenetically closely related, but nevertheless different, genera. Support for the separate generic status of the unknown human bacterium comes from the fact that it has a Lys-D-Asp type A $4 \alpha$ murein, whereas $G$. sanguis has a cell wall that is directly lysine crosslinked (type $\mathrm{A} 1 \alpha$ ). Additional evidence for the separate generic status of the unknown coccus comes from its very characteristic phenotype, in particular its asaccharolytic nature. In contrast, $G$. sanguis is a highly saccharolytic organism (5). Characteristics which distinguish the unknown human bacterium and $G$. sanguis are shown in Table 2. Based on 16S rRNA sequence considerations and the distinctive phenotypic traits of the unknown coccus, we believe that this bacterium merits classification in a new genus and new species, for which the name Facklamia hominis is proposed.

Description of Facklamia gen. nov. Facklamia (Fack.lam'i.a. L.n. Facklamia, referring to Facklam, in honor of Richard R. Facklam, a contemporary American microbiologist, for his many contributions to the microbiology of the gram-positive cocci) cells are gram positive, non-spore forming, nonmotile, and spheroidal and occur in pairs or groups. Facultatively anaerobic and catalase negative. Voges-Proskauer negative. Acid is not produced from glucose and other sugars. Hippurate and starch are hydrolyzed. Arginine dihydrolase is produced. Nitrate is not reduced. The murein type is type A4 $\alpha$ (L-LysD-Asp). The $\mathrm{G}+\mathrm{C}$ content of the DNA is $41 \mathrm{~mol} \%$. The type species of the genus Facklamia is Facklamia hominis. As determined by $16 \mathrm{~S}$ rRNA gene sequence analysis, the genus Facklamia belongs to the lactic acid group of bacteria with low DNA $\mathrm{G}+\mathrm{C}$ contents and is phylogenetically closely related to $G$. sanguis, but is distinguished from the latter species by its type $\mathrm{A} 4 \alpha$ murein and the test results shown in Table 2.
Description of Facklamia hominis sp. nov. Facklamia hominis (ho'mi.nis. L.gen.n. hominis, of human, from which the organisms were isolated) cells are gram positive and ovoid and occur in pairs or groups. Cells are nonpigmented and nonmotile. Spores are not produced. Facultatively anaerobic and catalase negative. Growth occurs on $5 \%$ blood agar, producing a weakly alpha-hemolytic reaction. Grows in the presence of $5 \% \mathrm{NaCl}$. Acid is not produced from amygdalin, L-arabinose, D-arabitol, cellobiose, glucose, inulin, glycogen, lactose, maltose, D-mannose, melibiose, melezitose, mannitol, lactose, pullulan, D-raffinose, D-ribose, sorbitol, sucrose, D-xylose, L-xylose, D-tagatose, or trehalose. Arginine dihydrolase and leucine arylamidase are produced. Alkaline phosphatase, $\beta$-glucuronidase, $\beta$-glucosidase, $\beta$-mannosidase, pyrazinamidase, phosphoamidase, valine arylamidase, chymotrypsin, and trypsin are not produced. Urease, alanylphenylalanylproline arylamidase, $\alpha$-galactosidase, glycyltryptophan arylamidase, pyrrolidonyl arylamidase, and pyroglutamine arylamidase may or may not be produced. Esculin and gelatin are not hydrolyzed. Hippurate is hydrolyzed. Voges-Proskauer and indole negative. Nitrate is not reduced. The $\mathrm{G}+\mathrm{C}$ content of the DNA is 41 mol\%. The cell wall murein type is L-Lys-D-Asp (type A4 $\alpha$ ). The type strain of $F$. hominis is CCUG 36813 . Strain CCUG $36813^{\mathrm{T}}$ was isolated from an abscess on buttocks and has the characteristics of the species. The type strain produces pyrrolidonyl arylamidase but not urease, glycyltryptophan arylamidase, or pyroglutamine arylamidase.

Nucleotide sequence accession number. The 16S rRNA gene sequence of strain CCUG $36813^{\mathrm{T}}$ has been deposited in the GenBank database under accession no. Y10772.

This work was supported in part by grants ERBCHRX-CT93-0194, BI02-CT93-0119, and BI02-CT94-3098 from the European Union.

\section{REFERENCES}

1. Aguirre, M., and M. D. Collins. 1992. Phylogenetic analysis of an unknown bacterium from human middle ear fluid: description of Alloiococcus otitis gen. nov., sp. nov. Int. J. Syst. Bacteriol, 42:79-83.

2. Aguirre, M., and M. D. Collins. 1992. Phylogenetic analysis of some Aerococcus-like organisms from urinary tract infections: description of Aerococcus urinae sp. nov. J. Gen. Microbiol. 138:401-405.

3. Aguirre, M., D. Morrison, B. D. Cookson, F. W. Gay, and M. D. Collins 1993. Phenotypic and phylogenetic characterization of some Gemella-like organisms from human infections: description of Dolosigranulum pigrum gen. nov., sp. nov. J. Appl. Bacteriol. 75:608-612

4. Bentley, R. W., J. A. Leigh, and M. D. Collins. 1991. Intrageneric structure of Streptococcus based on comparative analysis of small-subunit rRNA sequences. Int. J. Syst. Bacteriol. 41:487-494.

5. Collins, M. D., M. Aguirre, R. R. Facklam, J. Shallcross, and A. M. Williams. 1992. Globicatella sanguis gen. nov., sp. nov., a new gram-positive catalasenegative bacterium from human sources. J. Appl. Bacteriol. 73:422-437.

6. Collins, M. D., C. Ash, J. A. E. Farrow, S. Wallbanks, and A. M. Williams. 1989. 16S ribosomal ribonucleic acid sequence analyses of lactococci and related taxa. Description of Vagococcus fluvialis gen. nov., sp. nov. J. Appl. Bacteriol. 67:453-460.

7. Collins, M. D., R. R. Facklam, U. M. Rodrigues, and K. L. Ruoff. 1993. Phylogenetic analysis of some Aerococcus-like organisms from clinical sources: description of Helcococcus kunzii gen. nov., sp. nov. Int. J. Syst. Bacteriol. 43:425-429.

8. Devereux, J., P. Haeberli, and O. Smithies. 1984. A comprehensive set of sequence analysis programs for the VAX. Nucleic Acids Res. 12:387-395.

9. Felsenstein, J. 1989. PHYLIP-phylogeny inference package (version 3.2) Cladistics 5:164-166.

10. Garvie, E. I. 1978. Streptococcus raffinolactis (Orla-Jensen and Hansen): a group N streptococcus found in raw milk. Int. J. Syst. Bacteriol. 28:190-193.

11. Janssen, P. H., S. Evers, F. A. Rainey, N. Weiss, W. Ludwig, C. G. Harfoot, and B. Schink. 1995. Lactosphaera gen. nov., a new genus of lactic acid bacteria, and transfer of Ruminococcus pasteurii Schink 1984 to Lactosphaera pasteurii comb. nov. Int. J. Syst. Bacteriol. 45:565-571.

12. Pot, B., P. Vandamme, and K. Kersters. 1994. Analysis of electrophoretic whole-organism protein fingerprints, p. 493-521. In M. Goodfellow and A. G, O'Donnell (ed.), Modern microbial methods. Chemical methods in prokaryotic systematics. J. Wiley and Sons, Ltd., Chichester, United Kingdom.

13. Schleifer, K. H., and O. Kandler. 1972. Peptidoglycan types of bacterial cell walls and their taxonomic implications. Bacteriol. Rev. 36:407-477.

14. Williams, A. M., U. M. Rodrigues, and M. D. Collins. 1991. Intrageneric relationships of enterococci as determined by reverse transcriptase sequencing of small subunit rRNA. Res. Microbiol. 142:67-74. 